\title{
The use of the C-MAC videolaryngoscope for awake intubation in patients with a predicted extremely difficult airway: case series
}

This article was published in the following Dove Press journal:

Therapeutics and Clinical Risk Management

\author{
Tomasz Gaszyński \\ Department of Anaesthesiology and \\ Intensive Therapy, Medical University \\ of Łódź, Łódź, Poland
}

\begin{abstract}
The C-MAC videolaryngoscope was evaluated for intubation in patients with predicted extremely difficult airway. The presented cases are patients with neoplasm tumors in larynx. In all cases, awake intubation using C-MAC videolaryngoscope was performed in patients breathing spontaneously, under local anaesthesia, with oxygen administered via nasal catheter. All intubations were successful and uneventful. The pre-surgery examination (CT scans and fiberscope laryngeal examination) was compared with view of larynx obtained during laryngoscopy. Based on my experience, I assume that C-MAC videolaryngoscope is a very useful tool for anaesthesiologists and can be applied not only for unexpected difficult intubation but also for predicted difficult airway. Moreover, it could be used as an additional diagnosis tool before larynx surgery. The view obtained with the C-MAC videlaryngoscope corresponds with larynx examination performed before surgery, and could potentially reveal more details.
\end{abstract}

Keywords: videolaryngoscope, airway management, predicted difficult airways, C-MAC

\section{Introduction}

The C-MAC videolaryngoscope can be very effective and useful in adult airway management. ${ }^{1}$ I would like to share my experience regarding the use of the C-MAC videolaryngoscope for intubation of patients with a predicted extremely difficult airway. The presented cases consist of patients with laryngeal tumors (Table 1).

The patients were examined before surgery and their airways were classified as extremely difficult. In all cases, awake intubation using the C-MAC videolaryngoscope (Karl Storz GmbH, Tuttlingen, Germany) was performed. All patients received $100 \mu \mathrm{g}$ of dexmedetomidine (Orion Pharma, Espoo, Finland) and 0.1-0.2 mg of fentanyl intravenously for premedication. The airways were anesthetized topically with a lidocaine atomizer and, additionally, $2-4 \mathrm{~mL}$ of $1 \%$ lidocaine was injected through the cricothyroid membrane. Laryngoscopy was performed in patients breathing spontaneously and oxygen was administered via nasal cannulae. Written informed consent for publication was obtained from all patients. This study was approved by the Medical University of Łódź Ethics Committee (protocol number: RNN/75/12/KB; Chairperson: Professor P Polakowski).

\section{Case descriptions \\ Case I}

A 62-year-old male underwent laryngoscopy in relation to further examination of the laryngeal inlet tumor. The examination of patient's entry to the larynx with a fiber-optic 
Table I Description of cases

\begin{tabular}{|c|c|c|c|}
\hline Case & Description & $\begin{array}{l}\text { Comparison with } \\
\text { the C-MAC view }\end{array}$ & Conclusion \\
\hline 1 & $\begin{array}{l}\text { A } 62 \text {-year-old male underwent laryngoscopy in } \\
\text { relation to further examination of the laryngeal } \\
\text { inlet tumor }\end{array}$ & $\begin{array}{l}\text { Fiber-optic evaluation } \\
\text { before surgery }\end{array}$ & $\begin{array}{l}\text { The views achieved by the C-MAC were similar } \\
\text { to the fiber-optic one. The C-MAC may be used } \\
\text { for examination of the airway before ENT surgery }\end{array}$ \\
\hline 2 & $\begin{array}{l}\text { A 59-year-old male underwent laryngoscopy in } \\
\text { relation to further examination of the laryngeal tumor }\end{array}$ & $\begin{array}{l}\text { CT scans before } \\
\text { surgery }\end{array}$ & $\begin{array}{l}\text { The C-MAC videolaryngoscope provided the } \\
\text { laryngeal inlet view }\end{array}$ \\
\hline 3 & $\begin{array}{l}\text { An 85-year-old female with a laryngeal tumor } \\
\text { underwent tracheostomy }\end{array}$ & $\begin{array}{l}\mathrm{CT} \text { scans before } \\
\text { surgery }\end{array}$ & $\begin{array}{l}\text { The C-MAC videolaryngoscope provided the } \\
\text { laryngeal inlet view }\end{array}$ \\
\hline 4 & $\begin{array}{l}\text { A } 55 \text {-year-old female was admitted to the hospital } \\
\text { with difficulties in breathing }\end{array}$ & $\begin{array}{l}\text { US of the larynx } \\
\text { before surgery }\end{array}$ & $\begin{array}{l}\text { The C-MAC videolaryngoscope provided the } \\
\text { laryngeal inlet view }\end{array}$ \\
\hline 5 & $\begin{array}{l}\text { A } 63 \text {-year-old obese male }(1.78 \mathrm{~m}, 119 \mathrm{~kg}) \text { who was } \\
\text { admitted to the hospital with hoarseness }\end{array}$ & $\begin{array}{l}\text { Clinical examination - } \\
\text { indirect laryngoscopy }\end{array}$ & The C-MAC view provided a definite diagnosis \\
\hline 6 & $\begin{array}{l}\text { A } 69 \text {-year-old male was admitted to the hospital with } \\
\text { a tumor of the entry to the larynx for surgery }\end{array}$ & Fiber-optic evaluation & $\begin{array}{l}\text { A videolaryngoscope provided better visualization } \\
\text { of the laryngeal inlet than a fiber-optic scope }\end{array}$ \\
\hline 7 & $\begin{array}{l}\text { A } 65 \text {-year-old male was admitted to the hospital for } \\
\text { biopsy of a tumor of the laryngeal inlet }\end{array}$ & $\begin{array}{l}\text { The McGrath } \\
\text { series } 5 \text { view }\end{array}$ & The view achieved using the C-MAC was better \\
\hline
\end{tabular}

Abbreviations: CT, computed tomography; ENT, ear, nose and throat; US, ultrasound.

scope was performed before the operation by an ear, nose and throat (ENT) surgeon (Figure 1). Laryngoscopy was performed with the C-MAC videolaryngoscope using a standard size three blade after premedication and a topical anesthetic of the upper airway (Figure 2). Intubation was successful and without any complications. The views obtained by the fiber-optic scope and the C-MAC videolaryngoscope were very similar (Figures 1 and 2). I assumed that the C-MAC device could be used for examination of the airway before ENT surgery.

\section{Case 2}

A 59-year-old male underwent laryngoscopy in relation to further examination of the laryngeal tumor. The computed tomography (CT) scan revealed a tumor around the cricoid and thyroid cartilages on the left side, which included the anterior part of the vocal cords and the thyroid gland. The tumor diameter was $45 \mathrm{~mm} \times 41 \mathrm{~mm} \times 39 \mathrm{~mm}$. Laryngoscopy was performed with the C-MAC videolaryngoscope using a

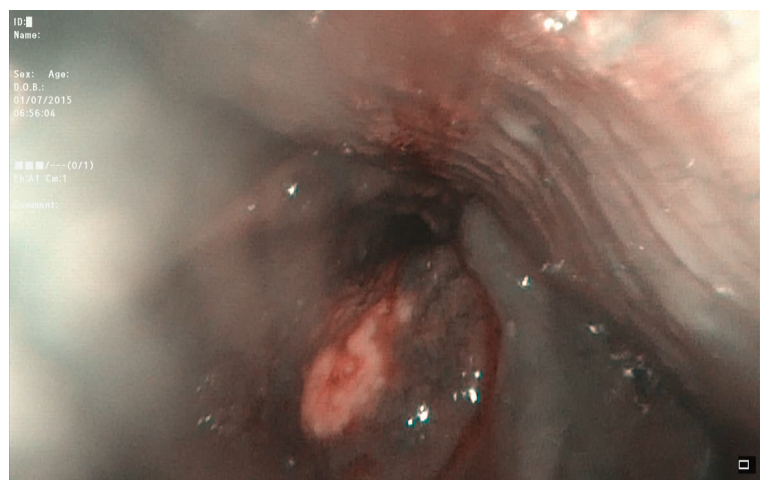

Figure I Case I: examination of patient's entry to the larynx with a fiber-optic scope performed by an ear, nose and throat surgeon before the operation. standard size three blade after premedication and a topical anesthetic of the upper airway. The view of the posterior part of the entry to the larynx was achieved and intubation was performed successfully without any complications.

\section{Case 3}

An 85-year-old female with a laryngeal tumor underwent tracheostomy. The CT scan before surgery revealed a tumor involving the palatine tonsils, the base of tongue, the supraglottic fossa and the epiglottis with a diameter of $40 \mathrm{~mm} \times$ $41 \mathrm{~mm} \times 48 \mathrm{~mm}$. This pathologic mass narrowed the lower pharynx and the entry to the larynx. Laryngoscopy was performed with the C-MAC videolaryngoscope using a standard size three blade after premedication and a topical anesthetic of the upper airway. A view of the entry to the larynx was achieved. Intubation was performed in a spontaneously ventilated patient without complications.

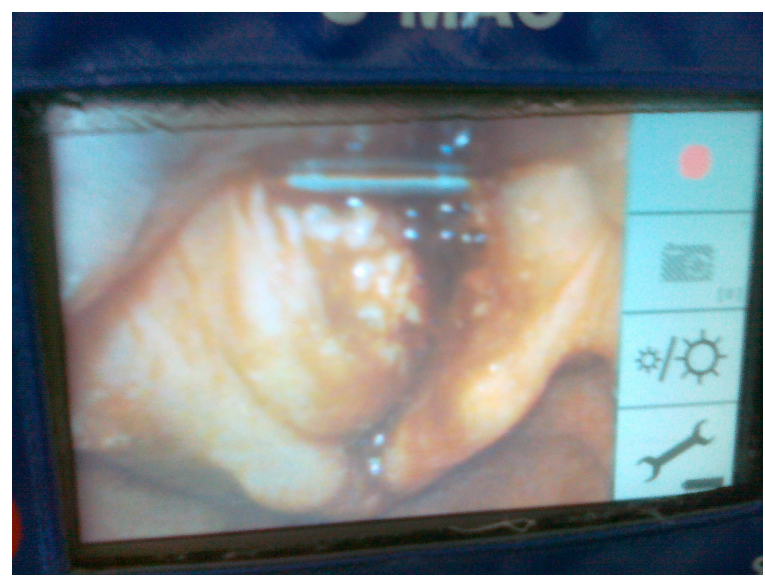

Figure 2 Case I: laryngoscopy was performed with the C-MAC videolaryngoscope. 


\section{Case 4}

A 55-year-old female was admitted to hospital with difficulties in breathing. The ultrasound examination showed a tumor involving the larynx and the trachea and narrowing the subglottic area. The visualization of the larynx with the C-MAC videolaryngoscope using a standard size three blade confirmed the narrowing of the subglottic area.

\section{Case 5}

This case is especially interesting. This is because a 63 -yearold obese male $(1.78 \mathrm{~m}, 119 \mathrm{~kg})$ who was admitted to the hospital with hoarseness was examined by an ENT surgeon (indirect laryngoscopy). He was not sure whether the patient had a polyp or a tumor of the entry to larynx. Laryngoscopy was performed with the C-MAC videolaryngoscope using a standard size three blade after premedication and a topical anesthetic of the upper airway. Laryngoscopy confirmed the tumor of the vocal cords.

\section{Case 6}

A 69-year-old male was admitted to the hospital with a tumor of the entry to the larynx for surgery. The fiber-optic examination before surgery showed tumor of the left part of the entry to the larynx occluding the glottis (Figure 3). The use of the C-MAC with a standard size three blade was associated with a better visualization of the vocal cords. This case showed that a videolaryngoscope could improve the visualization of the entry to the larynx. This is because the laryngoscope blade can elevate or push the tumor mass away from the center of the view, which is not possible when a fiber-optic scope is used.

\section{Case 7}

A 65 -year-old male was admitted to the hospital for biopsy of a tumor of the laryngeal inlet. The first attempt of

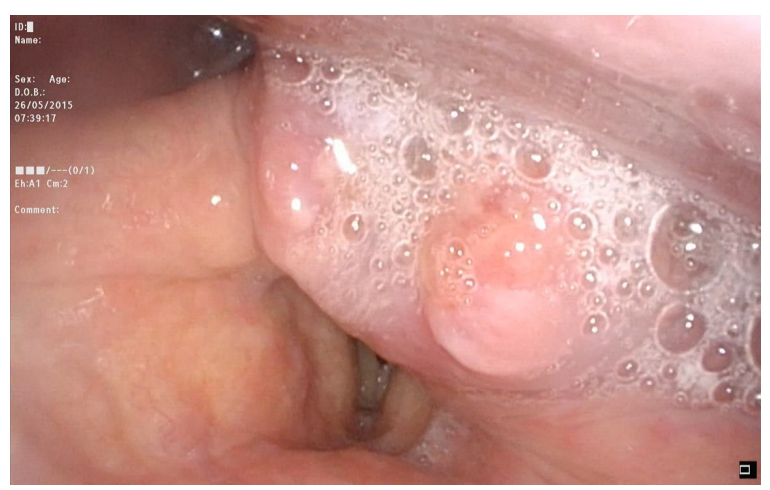

Figure 3 Case 6: fiber-optic examination before surgery. laryngoscopy was performed using the McGrath series 5 videolaryngoscope (Aircraft Medical, Edinburgh, UK) after premedication and a topical anesthetic of the upper airway. However, the achieved view was poor and I decided to change the videolaryngoscope to the C-MAC with a standard size three blade. The view achieved using the C-MAC was better and allowed safer intubation of the patient.

\section{Discussion}

The above-described cases confirm the use of the C-MAC videolaryngoscope in predicted difficult intubation. The C-MAC videolaryngoscope can be successfully used for awake intubations. The first case showed that the laryngeal view achieved with the C-MAC videolaryngoscope is similar to the one achieved with a fiber-optic scope during examination of the entry to the larynx by ENT surgeons. The second, third and fourth cases confirmed that the view of the laryngeal inlet corresponded with the CT and ultrasound scans done before surgery. The fifth case showed that the C-MAC videolaryngoscope could be used as an additional tool for examination of patients when indirect laryngoscopy was less accurate. The sixth case demonstrated that in some cases of tumors occluding the laryngeal inlet, fiber-optic evaluation before surgery can show less than the view achieved with a videolaryngoscope. This is because the laryngoscope blade can elevate or push the tumor mass away from the center of the view, which is not possible when a fiber-optic scope is used. The seventh case showed that videolaryngoscopes differ in design and features, which may influence the clinical performance and the achieved laryngeal view.

I have already described successful use of the C-MAC videolaryngoscope in morbidly obese patients who could be difficult to intubate. ${ }^{2}$ Aziz et al described the use of the C-MAC videolaryngoscope in patients with a predicted difficult intubation, but the patient selection for this study included patients with a reduced cervical mobility either from pathologic conditions or from cervical spine precautions (limited capacity to flex or extend the neck or managed with a cervical collar but with a negative imaging), Mallampati score of III or IV, reduced mouth opening $(<3 \mathrm{~cm})$ or history of difficult direct laryngoscopy. ${ }^{3}$ There were no patients with tumors of the entry to the larynx in this study. Similarly, Noppens et al recorded that the use of the C-MAC videolaryngoscope improved both the laryngeal view and the intubating success rate at the first attempt in patients with predictors for difficult intubation in the intensive care unit setting. ${ }^{4}$ However, again in the evaluated population, there were no patients with laryngeal tumors. 
Awake intubation with the C-MAC videolaryngoscope was described by Kramer et al. ${ }^{5}$ They included in their study patients with limited mouth opening, but without laryngeal tumors. They found that there was no difference in the success rate of intubation and in the satisfaction of anesthetists and patients. They concluded that in an anticipated difficult nasal intubation, a videolaryngoscope represents an acceptable alternative to fiber-optic intubation. Our experience confirms the observation that the C-MAC videolaryngoscope can be used for awake intubation in patients with predicted difficult airways.

In the seventh case, I compared the achieved view of the entry to the larynx using the McGrath series 5 videolaryngoscope and the C-MAC in the same patient with a laryngeal tumor. The use of the C-MAC videolaryngoscope was associated with a better view of the laryngeal inlet and allowed safer intubation. I have also described a similar case before. ${ }^{6}$ Those cases showed that a view achieved with different videolaryngoscopes could differ significantly and the laryngoscopic view achieved with the C-MAC could be better than the one achieved with other videolaryngoscopes.

The use of the C-MAC as a standard practice in patients for ENT surgery was suggested by Meininger et al. ${ }^{7}$ They performed intubation which compared direct laryngoscopy and the C-MAC view in 108 ENT patients. A better view was achieved with the C-MAC device. Despite the excellent visualization of the glottis with the C-MAC videolaryngoscope, there is always a possibility of a difficult insertion of the tracheal tube. This is in particular true in patients with distorted anatomy where there is little room for manipulation. ${ }^{8}$ This problem can be overcome by using an adjunct, for example, Frova introducer, as described by Vinayagam et al. ${ }^{9}$ I have also described the use of a fiber-optic scope as a "smart stylet" technique. ${ }^{10}$

\section{Conclusion}

I assume that the C-MAC videolaryngoscope is a very useful tool for an anesthetist and can be used not only for unexpected difficult intubation but also for predicted difficult airway, as well as an additional diagnostic tool before ENT surgery. The view achieved with the C-MAC videolaryngoscope corresponds to the examination of the larynx performed before surgery or may even show more details.

\section{Acknowledgment}

English correction performed by Dawid Aleksandrowicz, MD, Department of Anaesthetics, Guy's and St Thomas' NHS Foundation Trust, London, UK is acknowledged.

\section{Disclosure}

The author reports no conflicts of interest in this work.

\section{References}

1. Xue FS, Li HX, Liu YY, Yang GZ. Current evidence for the use of C-MAC videolaryngoscope in adult airway management: a review of the literature. Ther Clin Risk Manag. 2017;13:831-841.

2. Gaszyński T. Clinical experience with the C-Mac videolaryngoscope in morbidly obese patients. Anaesthesiol Intensive Ther. 2014; 46(1):14-16.

3. Aziz MF, Dillman D, Fu R, Brambrink AM. Comparative effectiveness of the C-MAC video laryngoscope versus direct laryngoscopy in the setting of the predicted difficult airway. Anesthesiology. 2012;116(3): 629-636.

4. Noppens RR, Geimer S, Eisel N, David M, Piepho T. Endotracheal intubation using the C-MAC video laryngoscope or the Macintosh laryngoscope: a prospective, comparative study in the ICU. Crit Care. 2012; 16:R103.

5. Kramer A, Muller D, Portner R, Mohr C, Groeben H. Fibreoptic vs. videolaryngoscopic (C-MAC D-BLADE) nasal awake intubation under local anaesthesia. Anaesthesia. 2015;70:400-406.

6. Gaszyński T. Comparison of the C-Mac video laryngoscope with the McGrath Series 5 video laryngoscope concerning an extremely difficult airway. Anaesthesiol Intensive Ther. 2016;48:55-57.

7. Meininger D, Strouhal U, Weber CF, et al. Direct laryngoscopy or C-MAC video laryngoscopy? Routine tracheal intubation in patients undergoing ENT surgery. Anaesthesist. 2010;59(9):806-811.

8. Cavus E, Kieckhaefer J, Doerges V, Moeller T, Thee C, Wagner K. The C-MAC ${ }^{\circledR}$ videolaryngoscope: first experiences with a new device for videolaryngoscopy-guided intubation. Anesth Analg. 2010;110: 473-477.

9. Vinayagam S, Dhanger S, Tilak P, Gnanasekar R. C-MAC ${ }^{\circledR}$ video laryngoscope with D-BLADETM and Frova introducer for awake intubation in a patient with parapharyngeal mass. Saudi J Anaesth. 2016;10(4): 471-473.

10. Gaszyński T. A combination of KingVision videolaryngoscope and flexible fibroscope for awake intubation in patient with laryngeal tumor-case report and literature review. Anaesthesiol Intensive Ther. 2015;47:433-435.
Therapeutics and Clinical Risk Management

\section{Publish your work in this journal}

Therapeutics and Clinical Risk Management is an international, peerreviewed journal of clinical therapeutics and risk management, focusing on concise rapid reporting of clinical studies in all therapeutic areas, outcomes, safety, and programs for the effective, safe, and sustained use of medicines. This journal is indexed on PubMed Central, CAS,

\section{Dovepress}

EMBase, Scopus and the Elsevier Bibliographic databases. The manuscript management system is completely online and includes a very quick and fair peer-review system, which is all easy to use. Visit $\mathrm{http}: / /$ www.dovepress.com/testimonials.php to read real quotes from published authors. 